\title{
Academic Freedom
}

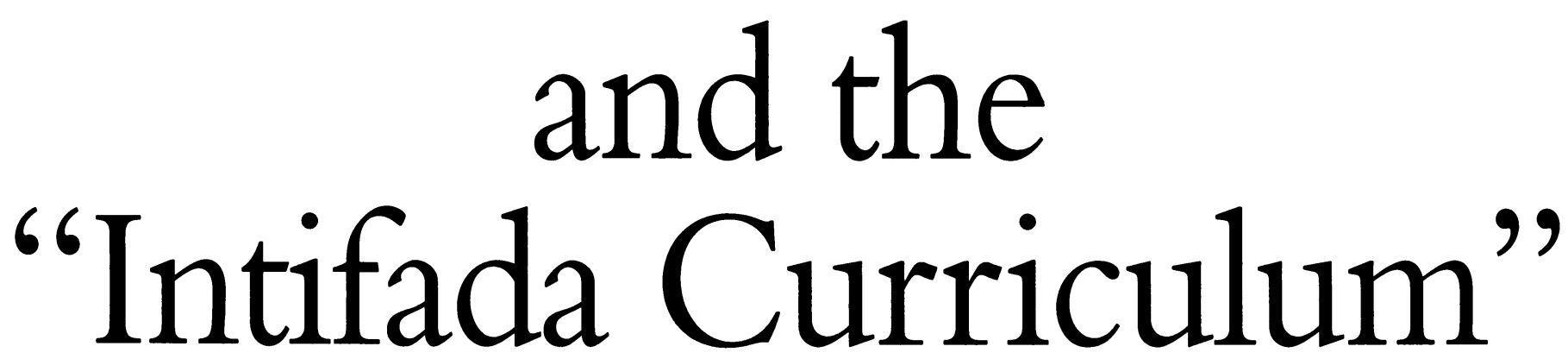

By ROBERT C. POST

In early May 2002, the English department of the University of Califomia, Berkeley, published a description on its Web site of a section of English R1A, a course in basic reading and writing skills. The course was titled "The Politics and Poetics of Palestinian Resistance." The course description explained, in provocative terms, the context of the Palestinian Intifada and its relationship to Palestinian writing; it closed with the waming that "conservative thinkers are encouraged to seek other sections." The course description quickly became a hot topic in the national media, with an appearance by the course instructor, a graduate student, on CNN's Hardball. An editorial in the Wall Street Journal decried the "Intifada curriculum" as one symptom of American universities' being "beholden to leftist ideologies."

Taken by surprise, the UC Berkeley English department asked the course instructor to revise his description. By July, working with the department, the instructor had published a new description. During the same time, the president of the University of Califormia, Richard Atkinson, asked Robert C. Post, the author of the text that appears below, to review the issues of academic freedom and governance raised by the controversy surrounding the course. Here is Post's August 12, 2002, letter to Atkinson, reprinted with the omission of some footnotes.

\section{DEAR PRESIDENT ATKINSON:}

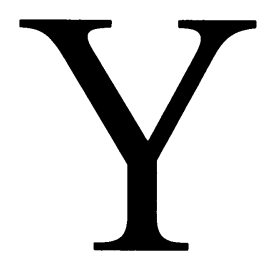

ou have asked me to discuss the issues of academic freedom and responsibility raised by the controversy surrounding "The Politics and Poetics of Palestinian Resistance," a section of English R1A to be taught in fall 2002 at the University of California, Berkeley.

These issues are multiple, novel, and complex. Because time is short, I can at best offer a preliminary evaluation that seeks to identify the most prominent of these issues and to suggest how they might be analyzed and resolved.

English R1A is a course that instructs undergraduates in basic skills of reading and writing. The course is offered in approximately sixty sections, each designed and taught by a graduate student instructor. The section entitled "The Politics

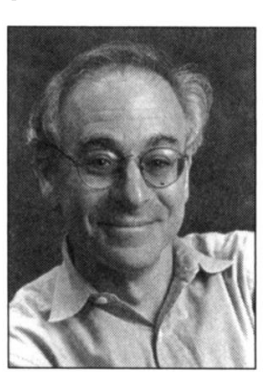
and Poetics of Palestinian Resistance" became controversial because of its initial course description, which read:

Robert Post is Alexander F. and May T. Morrison Professor of Law at the University of Califormia, Berkeley, and a member of the AAUP's Committee A on Academic Freedom and Tenure.
Course Description. Since the inception of the Intifada in September of 2000, Palestinians have been fighting for their right to exist. The brutal Israeli military occupation of Palestine, an occupation that has been ongoing since 1948 , has systematically displaced, killed, and maimed millions of Palestinian people. And yet, from under the brutal weight of the occupation, Palestinians have produced their own culture and poetry of resistance. This class will examine the history of the Palestinian resistance and the way that it is narrated by Palestinians in order to produce an understanding of the Intifada and to develop a coherent political analysis of the situation. This class takes as its starting point the right of Palestinians to fight for their own self-determination. Conservative thinkers are encouraged to seek other sections.

This course description was plainly unacceptable. After much discussion and many drafts, the description, which is posted on the Web site of the Berkeley English department, was altered to read:

This is a course on Palestinian resistance poetry. It takes as its point of departure the Palestinian literature that has developed since the creation of the state of Israel in 1948, which has displaced, maimed, and killed many 
Palestinian people. The Israeli military occupation of historic Palestine has caused unspeakable suffering. Since the occupation, Palestinians have been fighting for their right to exist. And yet, from under the weight of this occupation, Palestinians have produced their own culture and poetry of resistance. This class will examine the history of the Palestinian resistance and the way that it is narrated by Palestinians. This class takes as its conceptual starting point the right of Palestinians to fight for their own self-determination. Discussions about the literature will focus on several intersecting themes: how are Palestinian artists able to imagine art under the occupation; what consequences does resistance have on the character of the art that is produced (i.e., why are there so few Palestinian epics and plays and comedies); can one represent the Israeli occupation in art; what is the difference between political art and propaganda and how do the debates about those terms inflect the production of literature; how do poems represent the desire to escape and the longing for home simultaneously (alternatively, how do poems represent the nation without a state); what consequence do political debates have on formal innovations and their reproduction; and what are the obligations of artists in representing the occupation? This $1 \mathrm{~A}$ course offers students frequent practice in a variety of forms of discourse leading toward exposition and argumentation in common standard English. The course aims at continuing to develop the students' practical fluency with sentence, paragraph, and thesis-development skills but with increasingly complex applications. Students will be assigned a number of short essays (two to four written pages) and several revisions.

This version of the course description was subsequently approved by the Berkeley Division of the Academic Senate.

At least three distinct questions may be asked of "The Politics and Poetics of Palestinian Resistance": (1) Is it proper for a course to use the literature of the Palestinian people in order to teach basic skills in reading and writing? (2) Was it proper for the Academic Senate to approve the final version of the course description? (3) Will the actual teaching of the course be consistent with academic standards?

The first question is easily answered. The general design of "The Politics and Poetics of Palestinian Resistance" is clearly acceptable. Basic reading and writing skills are now commonly taught in the context of close textual study. Most major universities believe that any reasonably sophisticated set of texts can be used for this purpose, and the literature of the Palestinian people certainly meets this test. The only question is whether the political debate that surrounds the IsraeliPalestinian controversy is so distracting as to render this literature an inappropriate vehicle for the study of basic skills in reading and writing. The University of California offers instruction in such skills, however, precisely so that our students can learn to think and write about issues that are of importance to them, and these issues are frequently contentious. We seek to inculcate skills that are relevant to a world of engaged and sometimes tempestuous citizenship, and in that context the controversial nature of the reading list of "The Politics and Poetics of Palestinian Resistance" can actually be seen as an asset rather than a liability.

The second question, by contrast, is difficult and uncertain. The exact status of course catalogues is an unresolved question. The regents [of the University of California] have allocated supervision over the content of course catalogues to the Academic Senate. Standing Order 105.2 delegates to the senate the power to "authorize and supervise all courses and curricula" offered in the University of California. In practice, this power is exercised by the "committees on courses" that operate on each campus. It is pursuant to this practice that the Berkeley Division of the Academic Senate has approved the reading list and the final version of the course description of "The Politics and Poetics of Palestinian Resistance."

Standing Order 105.2 represents the regents' commitment to a principle of academic freedom that is historically and theoretically fundamental: university scholarship, and the teaching that expresses and transmits that scholarship, is to be understood as a matter of professional knowledge. It follows from this principle that evaluation of scholarship and teaching is to be entrusted to the judgment of competent professionals, in the form of the corporate body of the faculty. This principle underlies the academic freedom of the entire university, because it distinguishes the enterprise of scholarship from the political governance of the state. The maintenance of this distinction is one of the great achievements of public higher education in the United States. Modern scholarship is built on a foundation that requires the professional autonomy of the professoriate.

If Standing Order 105.2 expresses a norm of professional autonomy, the Academic Senate, in exercising that autonomy, must be guided by a second fundamental principle of academic freedom: individual faculty are to be accorded broad freedoms independently to think, write, and engage in research. These freedoms are necessary if the university is to fulfill its function of promoting the advancement of knowledge.' Analogous freedoms extend to teaching, where faculty report and explore the results of their scholarly endeavors. ${ }^{2}$ Course descriptions are properly characterized as an aspect of teaching, because they initiate the pedagogical relationship between individual faculty and their students.

Senate review of course descriptions, therefore, must both ensure that professional standards have been satisfied and also accord individual faculty members substantial freedom to pursue their own pedagogical agendas. These potentially conflict- 
ing imperatives can be reconciled if the senate approves course descriptions whenever relevant professional standards have been satisfied. Put another way, the senate should not seek to regulate course descriptions for reasons that are unrelated to pertinent professional standards. This implies that it would be improper for the Academic Senate to disapprove the course description of "The Politics and Poetics of Palestinian Resistance" because it might anger state politicians, who might punish the university. It would be equally improper for the Academic Senate to disapprove the course description because it might outrage alumni, who might reduce their annual contributions to the university. The authority of the senate to regulate course descriptions extends only to the application of standards inherent in the professional enterprise of scholarship and teaching.

This threshold test excludes two common objections to the course description of "The Politics and Poetics of Palestinian Resistance." It is argued, first, that permitting the description to remain on the English department Web site will place the

university in the unacceptable position of endorsing its inflammatory ideas. This objection rests on the premise that the university endorses the scholarship and teaching of its professors. The premise is fundamentally incompatible with the academic mission of the university. The university employs thousands of faculty members, who hold a myriad of different standpoints. The resulting diversity is a great strength of the university. This diversity would vanish, and scholarship and teaching would grind to a halt, were faculty to be prohibited from expressing ideas that the university could not itself endorse. It is therefore a basic postulate that the university no more endorses the diverse ideas of its faculty than it endorses the contents of the millions of books in its libraries. Whether faculty ideas are expressed in scholarly publications or in course descriptions, professional standards require that they be regarded as the viewpoint of individual professors, not those of the university.

Second, it has been argued that the course description of "The Politics and Poetics of Palestinian Resistance" should be regulated because it is offensive. A robust scholarly dialogue, however, can be fierce, consequential, and hurtful to those who care intensely about their ideals. It can produce the kind of offense experienced by persons when their most precious beliefs and convictions are ruthlessly attacked. The university cannot eliminate this form of offense without also strangling scholarly debate. This form of offense should be distinguished from that experienced by persons who are assaulted by vicious language that violates the basic norms of civility that underwrite the practice of rational deliberation.

Although university regulation of such language poses complex and difficult questions, it is sufficient for present purposes to note that the course description of "The Politics and Poetics of Palestinian Resistance" is not offensive in this way. It does not use vituperative epithets or hate speech. If the course description gives offense, it is because of the substance of its speech, rather than its manner. This kind of offense cannot be prevented without simultaneously suppressing the very academic exchange the university exists to promote. Professional standards therefore prohibit using such offense as a reason for regulating teaching or scholarship.

The proper principle that the Academic Senate should apply in reviewing the course description of "The Politics and Poetics of Palestinian Resistance" is whether the course description complies with relevant professional standards. We can summarize these standards in two requirements: course descriptions must be educationally justified, and they must not violate pertinent academic norms. ${ }^{3}$ Considering, first, the question of pedagogical justification, it may be argued that there is no good educational reason for the course description of "The Politics and Poetics of Palestinian Resistance" to include so vivid and forceful a statement of opposition to Israel's treatment of the Palestinians. There are exceptional circumstances, however, when the political viewpoint of faculty is relevant to how the material of a course will be engaged. When this happens, faculty disclosure of their viewpoint in a course description is justified because it enables students to make more informed choices in selecting their classes. It is thus not uncommon to see course descriptions that explicitly announce that a given class will be taught "from the perspective" of free market principles, human rights, or feminism. The pedagogical reasons for this kind of disclosure do not disappear merely because the perspective disclosed happens to be highly controversial or inflammatory.

In applying this analysis to the course description of "The Politics and Poetics of Palestinian Resistance," it is correct to observe that the description exposes the depth of the instructor's political opposition to Israel. This disclosure may be justified, however, because students can select among many sections of English R1A, and in deciding whether to enroll in "The Politics and Poetics of Palestinian Resistance," they may well want to know the nature and passion of the political perspective of the graduate student instructor offering the course. It is certain that this perspective will inform his approach to the Palestinian literature that will be studied. There are good pedagogical reasons, therefore, for the course description of "The Politics and Poetics of Palestinian Resistance" to disclose the intense political views of its instructor.

We must distinguish, however, between using a course description to provide students with pedagogically justified notice, and using a course description as a platform for political preaching. It is possible that the rhetoric of a course description can become so excessive or overreaching as to become a political tract that bears little or no relationship to the pedagogical justification of disclosure. Faculty members have no 
business using course descriptions for the mere purpose of disseminating their political views.

Determining exactly when a course description outruns the justification of disclosure and becomes instead an example of political preaching involves difficult questions of educational judgment. My own view is that in making such determinations the instructor ought to receive the benefit of the doubt, especially if a course description involves controversial matters, because in such circumstances there will be a strong and natural temptation to dampen the rhetoric of a course description for reasons that have nothing to do with professional standards. According to this view, the course description of "The Politics and Poetics of Palestinian Resistance" would be deemed justified if its rhetoric was arguably necessary in order to provide a pedagogically appropriate disclosure.

Course descriptions must not only be pedagogically justified, they must also comply with relevant academic standards. It might be said that the course description of "The Politics and Poetics of Palestinian Resistance" violates two such standards. The first concerns norms of academic inquiry. It might be argued that the rhetoric of the course description is so militant and one-sided that it is inconsistent with the requirement that scholarship and teaching proceed from an open mind and employ disinterested reason. Those who press this argument urge that the course description be modified so as to reflect both sides of the current debatefor example, by recognizing Israel's right to exist.

This objection, however, misunderstands norms of academic inquiry. Scholarship requires an open mind, but this does not mean that faculty members are unprofessional if they reach definite conclusions. It means rather that faculty must always stand ready to revise their conclusions in light of new evidence or further discussion. Scholarship also requires the exercise of disinterested reason, but this does not mean that faculty are unprofessional if they are urgently committed to a definite point of view. It means rather that faculty must form their point of view by applying professional standards of inquiry rather than by succumbing to external and illegitimate incentives such as monetary gain or political coercion.

There is no academic norm that prohibits scholarship from communicating definite viewpoints about important and controversial questions, like democracy, human rights, or the welfare state. Faculty must be free to communicate these viewpoints in their pedagogy. Political passion is in fact the engine that drives some of the best scholarship and teaching at the University of California, and this is particularly true in the humanities and social sciences.

The second academic standard implicated by the course description of "The Politics and Poetics of Palestinian Resistance" involves the academic freedom of students. The political values that faculty inevitably bring to a course, and which they may properly disclose in a course description, can sometimes be expressed in so harsh and excessive a way as to signal to students that differing views will be neither respected nor tolerated. A fundamental principle of university governance, however, requires that students be accorded the right to think freely and to exercise independent judgment. This principle follows from the educational mission of the modern university, which is to encourage students to enrich and deepen their own values and commitments. The principle requires that we evaluate our students solely on the merits of their work. We guarantee that students will not suffer merely because their political perspectives happen to differ from those of their instructor.

If a faculty member harshly expresses very strong political views, however, students may doubt this guarantee. There is thus tension between the necessary freedom of faculty to express their political perspectives, and the essential freedom of students to express differing views. Skillful faculty members can sometimes defuse this tension by acknowledging their own political commitments in the classroom. The disclosure can not only encourage students to perceive and discount the implicit bias of their instructor, but, if properly done, can also serve explicitly to authorize students to express different perspectives.

Unfortunately, the course description of "The Politics and Poetics of Palestinian Resistance" displays no such pedagogical subtlety. What made the original draft of the course description so coarse and unacceptable was its nearly explicit suggestion that the graduate student instructor would not tolerate student perspectives that differed from his own. (Recall that the original draft of the course description said that "conservative thinkers are encouraged to seek other sections.") In approving the final version of the course description of "The Politics and Poetics of Palestinian Resistance," therefore, a relevant issue before the Academic Senate was whether the language of the course description, even as modified, was so excessive as to convey the message that independent student views would not be respected.

The resolution of this issue is in part connected to the third question that I initially posed, which is whether the teaching of "The Politics and Poetics of Palestinian Resistance" will be consistent with academic standards. One can legitimately ask whether the graduate student instructor who wrote the highly improper first draft of the course description can be trusted to nurture the academic freedom of his students. It might be argued that modification of the course description is especially important because of the real possibility that he will subject his students to improper intimidation.

At the time the Academic Senate approved the course description of "The Politics and Poetics of Palestinian 
Resistance," the Berkeley campus had already taken numerous steps to ensure that the class would be taught in a manner that complied with relevant academic norms. Berkeley faculty members had spoken at length with the instructor, and they reported that he had become thoroughly aware of his obligations and responsibilities as an instructor at the University of California. The Berkeley English department undertook explicitly to advise students enrolled in the course that they would have the right to express themselves freely and to have their work evaluated without discrimination or harassment. The department made its chair available to hear complaints about the conduct of the course. And the department took the extraordinary step of requiring that a full tenured member of the faculty observe the class to ensure that it would be taught in a way that was entirely consistent with applicable academic standards.

Since the class is likely to cause controversy in the fall, the presence of this observer will serve to protect both the graduate student instructor and his students. ${ }^{+}$The presence of such an observer is certainly an extraordinary event. It is not clear that an analogous requirement could be imposed upon a class taught by a full member of the faculty. It may well be permissible in this case, however, because the instructor is a graduate student who is in my judgment a kind of apprentice under the tutelage of the faculty.

In light of these several unusual precautions, we can have some confidence that "The Politics and Poetics of Palestinian Resistance" will actually be taught in a manner that is consistent with academic standards. This conclusion is relevant to evaluating the propriety of the course description, because a major objection to that description is its possible intimation that students will be judged on their politics rather than on the merits of their work. Because we can be reasonably confident that students in the class will in fact have their academic freedom respected, the force of this objection is somewhat diminished. Regulating the course description in order to protect students from intimidation thus becomes a less pressing concern.

At the outset of this letter, I identified three questions that may be asked of "The Politics and Poetics of Palestinian Resistance." We have concluded in answer to these questions that "The Politics and Poetics of Palestinian Resistance" is a properly designed course that will in all likelihood be taught in a manner that is consistent with academic standards. There are, however, possible deficiencies in its course description, which turn on whether its inflammatory language is so overwrought as to be intimidating, or so obstreperous as to be pedagogically unjustified. The Academic Senate has decided that the course description is acceptable, that it is neither intimidating nor without educational justification. This decision is no doubt disputable, because it involves hard and close matters of educational judgment about which reasonable per- sons can disagree. It is nevertheless a defensible decision, because good reasons can be articulated in its support. To use legal terminology, the decision does not constitute an abuse of discretion. As I have discussed, weighty reasons of academic freedom counsel that decisions within the professional expertise of the faculty that do not constitute an abuse of discretion be respected by the administration of the university, even if members of the administration would have reached a different judgment had they had been called upon to make an initial determination. The professional autonomy of the faculty inheres in such deference.

Please do not hesitate to let me know if I can be of any further assistance in this matter.

Sincerely,

ROBERT POST 